\title{
Rock Deformation Behavior Near Excavations Under the Influence of High Tectonic Stress in Coal Seam V-12, "Severnaya" Mine, JSC "Urgalugol"
}

\author{
Pavel Grechishkin ${ }^{*}$, Evgeny Razumov ${ }^{1}$, Olga Petrova ${ }^{1}$, Alexey Kozlov², and Evgeny \\ Aushev $^{3}$ \\ ${ }^{1}$ Kuzbass State Technical University named after T.F. Gorbachev, branch in the city of Prokopyevsk, \\ 19A, Nogradskaya Str., Prokopievsk, 653033, Russia. \\ ${ }^{2}$ JSC "Urgalugol”, 2 Magistralnaya Str., Khabarovsk region, Verchnebureinsky District, Chegdomyn, \\ 682030, Russia. \\ 3“"RANK 2” Ltd., 119 Kuznetsky Ave., Kemerovo, 650055, Russia.
}

\begin{abstract}
The article is devoted to determination of roof bolt parameters in coal mine excavations when there is rather high tectonic stress. The work was complicated by the presence of considerable number of fractures in the adjacent rock of seam V-12 in "Severnaya" mine (JSC "Urgalugol") as well as variable stress field, low roof rock strength and heterogeneity, considerable rock shift during excavations development and maintenance. The article presents the results of horizontal and vertical stress measurements in the rock mass, physical and mechanical properties, roof rock structure and fracturing. According to the results of boreholes study by means of borehole endoscope the authors fully confirmed the forecasted parameters of areas with roof rock discontinuity, the boundaries of unstable rock. The article presents the measurement results of roof rock shift during development face advance. Based on the research, recommendations on excavations development and proper support using were given under conditions of seam V-12 in "Severnaya" mine (JSC "Urgalugol").
\end{abstract}

\section{Introduction}

Within last decade mines have begun to use intensive coal mining technology it turned out that current regulatory documents can be poorly adaptive to the new organizational and technical conditions of the working mines, and that due to frequent accidents and downtime in longwalls and development faces does not make it possible to enhance labor efficiency sufficiently and increase coal output using underground mining method [1]. As a result, some companies carry out scientific work aimed at studying mining, geological and technical conditions of intensive mineral resources extraction to gain and generalize practical experience and study results [2-4]. As a rule, different scientific and research companies do

\footnotetext{
* Corresponding author: pv_grechishkin@mail.ru
} 
such research. The main goal of these companies is to implement the results of their studies in practice in coal mines and classify the guidelines for correction of the current regulatory documents.

The authors of the article have done the same work under conditions of "Severnaya" mine (JSC "Urgalugol") during seam V-12 mining on level +200 (about $230 \mathrm{~m}$ deep, maximum mining depth was $340 \mathrm{~m}$ ). According to the results of preliminary survey and evaluation of mine excavations operation conditions the authors determined the following differences from the current regulatory documents:

- shifting of ribs, roof and floor of the excavations, especially at the intersection of the excavations and longwall, can reach $20 \%$ of the design size;

- falling in of roof rock in the development faces when they head to each other leads work stoppage and downtime up to accident response and recovery;

- sufficient variety in shifting of excavation ribs at their different positioning in reference to the meridian, which shows that there is heterogeneous tectonic stress field;

- vertical deformations of roof lead to the failure of the main support (rock bolts);

- in high rock pressure areas there are failures of the secondary support cable bolts.

The factors having negative effect on stability of excavations include geological faults, laminated and fractured roof rock, local zones with low rock strength, variation in coal seam thickness and properties of coal and rock, heterogeneous tectonic stress field.

The authors determined the goal and objectives of the study considering the importance of such work at present moment and influence of the factors mentioned above. They developed the sequence of procedures and chose proper methods to carry out an experiment under conditions of "Severnaya" mine (JSC "Urgalugol").

\section{Materials and methods}

The goal of the studies is to develop methodological guidelines which secure operational conditions of the excavations under conditions of "Severnaya" mine (JSC "Urgalugol").

According to the goal of the study the authors have set and met the following scientific and practical objectives:

- to determine the trends in physical and mechanical properties distribution in different parts of the mine field using rock samples taken out at boreholes drilling in the roof of the excavations;

- to determine the intensity of fracture distribution in the roof rock according to the results of borehole studies by means of borehole endoscope;

- to determine the direction and value of tectonic stress vector by means of partial coal mass relaxation in the face and ribs);

- to test the input parameters of the software using finite elements method according to the results of the experiment;

- to perform numerical modeling of geomechanical processes in a wide range of mining, geological and technical conditions and establish the parameters of supports to be used in excavations according to estimated stress and potentially unstable rock mass around an underground excavation;

- to reveal the parameters of tectonic field stress vector based on the results of numerical modeling and determine its influence on excavations which are drifted in different locations and parameters of the supports;

- to confirm the compliance of the forcasted parameters with real deformation parameters of the rock enclosing the excavations according to the results of the geomechanical processes monitoring. 
These objectives were included in the research program. The results of the research are given below.

\section{Results and discussion}

The authors determined the trends in physical and mechanical properties distribution in different parts of the mining field according to rock samples testing. They found out that roof rock thickness and structure of seam V-12 are very heterogeneous. Immediate roof rock thickness varies from 2,0 up to 7,0 m. To make quantitative assessment of immediate roof parameters the authors did additional mine research which included borehole drilling in the roof, taking samples (drill samples), analysis of roof rock composition using borehole video endoscope.

11 drill samples were taken out of seam V-12 roof within three extraction areas. Results of measurements and tests of these samples were used as basic data at software testing and project documents correction.

According to the results of studies using borehole endoscope the authors estimated the intensity of fracture spread in the rock roof. They determined considerable discontinuity and heterogeneity of rock and coal mass. They include argillite and siltstone, carbon-bearing interbeddings and thin layers of sandstone and tuffite.

To determine directions and values of tectonic stress vector the authors carried out nine experiments to perform partial relaxation of coal mass in the face and ribs of excavations with changes in the deformation values.

The authors used the following scheme of the research: they installed dial gauge on the rib of the excavation in three directions; drilled a relaxation hole and determined deformations, installed a hydraulic jack into the borehole and gradually loaded the seam edge till coal broke down. The authors wrote down manometer and dial gauge readings [5]. After the results of the experiment were processed the authors determined the elasticity modulus, coal compression strength, values and direction of main stress vector (Table 1).

Table 1. Results of stress measurement in coal seam V-12.

\begin{tabular}{|c|c|c|c|c|}
\hline \multirow{2}{*}{ Test No } & \multicolumn{2}{|c|}{ Stress, MPa } & \multirow{2}{*}{$\begin{array}{c}\text { Angle } \boldsymbol{\varphi}^{*}, \\
\text { degree. }\end{array}$} & $\begin{array}{c}\text { Elasticity } \\
\text { modulus, MPa }\end{array}$ \\
\cline { 2 - 3 } & $\boldsymbol{\sigma}_{\mathbf{1}}$ & $\boldsymbol{\sigma}_{\mathbf{2}}$ & 23 & 2797 \\
\hline 1 & 8,31 & 20,58 & 44 & 2174 \\
\hline 2 & 10,35 & 6,85 & 24 & 3678 \\
\hline 3 & 11,9 & 4,13 & 21 & 3787 \\
\hline 4 & 7,44 & $-8,74$ & -7 & 3636 \\
\hline 5 & 7,59 & $-3,84$ & 1 & 726 \\
\hline 6 & 7,56 & 1,64 & -23 & 1282 \\
\hline 7 & 7,28 & 9,75 & 38 & 2161 \\
\hline 8 & 6,57 & 19,38 & -19 & 2770 \\
\hline 9 & 9,52 & 4,34 & \\
\hline
\end{tabular}

$\varphi^{*}$ - angle between $\mathrm{X}$-axis and main maximum stress vector.

According to Table 1, stress field in the coal and rock mass under seam V-12 conditions of JSC "Urgalugol" is very heterogeneous. That is due to the high level of rock mass fracturing and complex pattern of tectonic stress field. Some tests revealed that in some cases horizontal stress can be 2,5-3,0 times higher than vertical stress. According to tests 4 and 5, there is tension stress in the right and left ribs of the conveyer roadway. That can be explained by the fact that the measurements were taken in area where there is influence of various rupture-type small-amplitude fractures. 
The results of parameter measurements of strain-stress behavior and experiments were used to adjust input parameters of the software using finite elements method.

The authors determined the trends in display of rock pressure intensity on the direction of development faces advance and their position in relation to the line perpendicular to geological faults (Figure 1).
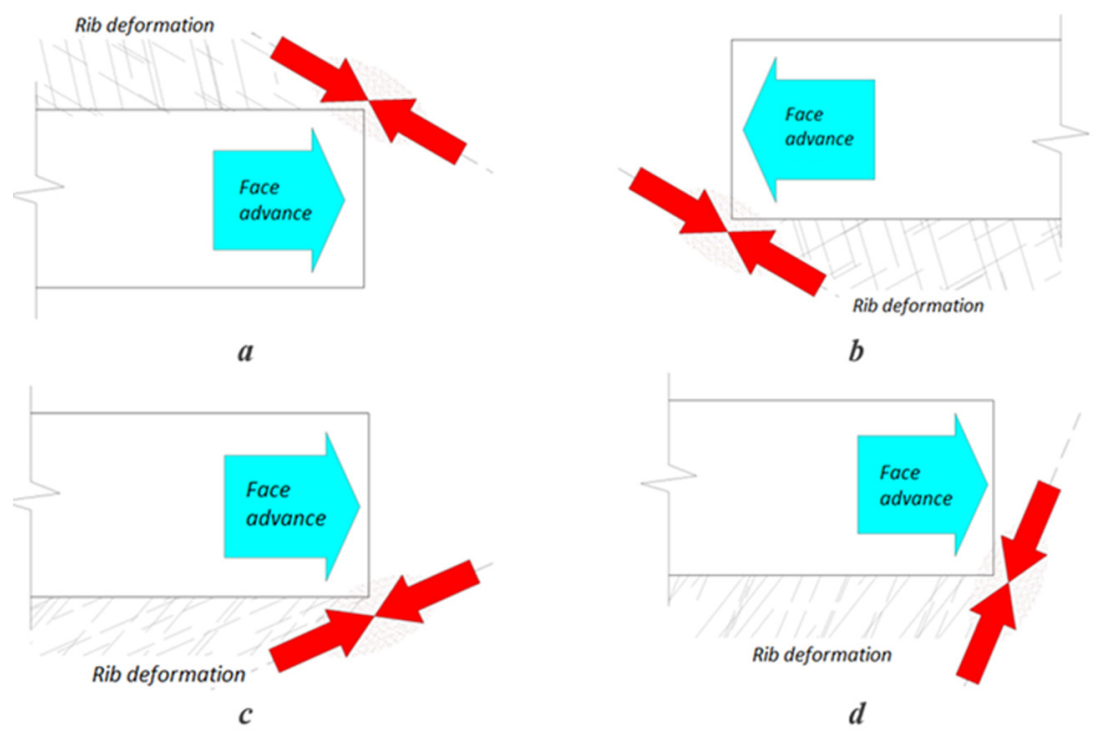

$\Rightarrow$ - main horizontal stress direction

Fig. 1. Type of coal destruction in the ribs of the excavations and roof rock falls depending on the direction and maximum horizontal stress vector (red arrows): a - airways and conveyer roadways (mining direction - from the main excavations to the lateral excavations); $b$ - airways and conveyer roadways (mining direction - from the lateral excavations to the main excavations); $\mathrm{c}$ - airways and connection excavations (mining direction - up-dip); $\mathrm{d}$ - installation chambers (mining direction down-dip).

The most intensive rock and coal crashing takes place in the ribs of the excavation when main horizontal stress vector is directed almost at a right angle to the axis of the excavation (Figure 1b). When the angle between the direction of the face advance and main horizontal stress vector is acute coal distruction in the ribs of the excavations is less intensive. But in this case roof rock shift and volume of coal fall increase in the area adjacent to the face, especially in areas where there is maximum stress concentration (Figure 1 a-c) [6-9]. The authors found considerable damage of rock bolts in these areas of the excavations. They found deformations on the support elements, regular breaks of the rock bolts and cable bolt shafts, nuts tearing off the first level cable bolts. These phenomena took place in roof and ribs of the excavation depending on its advance direction.

According to the results of numerical modelling made using finite elements method, the authors determined the parameters of rock destruction adjacent to mine excavations. The models were developed considering information given in sources 10-15. As for areas outside high stress zone and longwall influence on the excavation, the authors forecasted two factured zones: arched zone (with depth up to $2,4 \mathrm{~m}$ from the roof) and a local one (at the depth of about 4-4,3 m).

To determine the causes of such an abnormal display of rock behavior in tectonic stress field the authors took measurements of roof rock shifts at drift advance using multiwire extensometers. The installation diagram of three-wire extensometer (RG3 type) in connection \#8 near drifting face is given in Figure 2. The sets of three-wire extensometers RG3-1 and 
RG3-2 were placed at a depth of $8,0 \mathrm{~m}, 4,0(4,1) \mathrm{m}$ and $1,85 \mathrm{~m}$ in two boreholes in the crosscut of the excavation. The research results are given below.

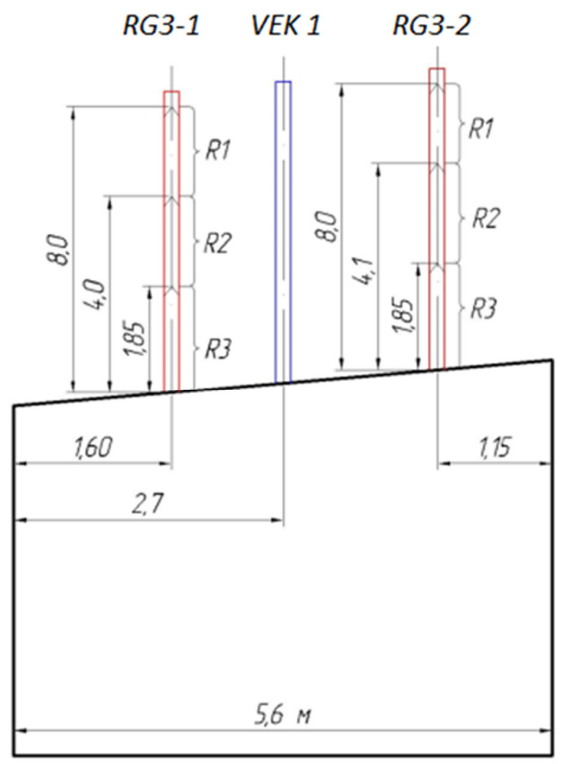

Fig. 2. Scheme of multiwire extensometers placement.

Measurements of multiwire extensometer were taken 1, 6, 10 and $14 \mathrm{~m}$ away from the face. The diagram in Figure 3 gives the multiwire extensometer data.

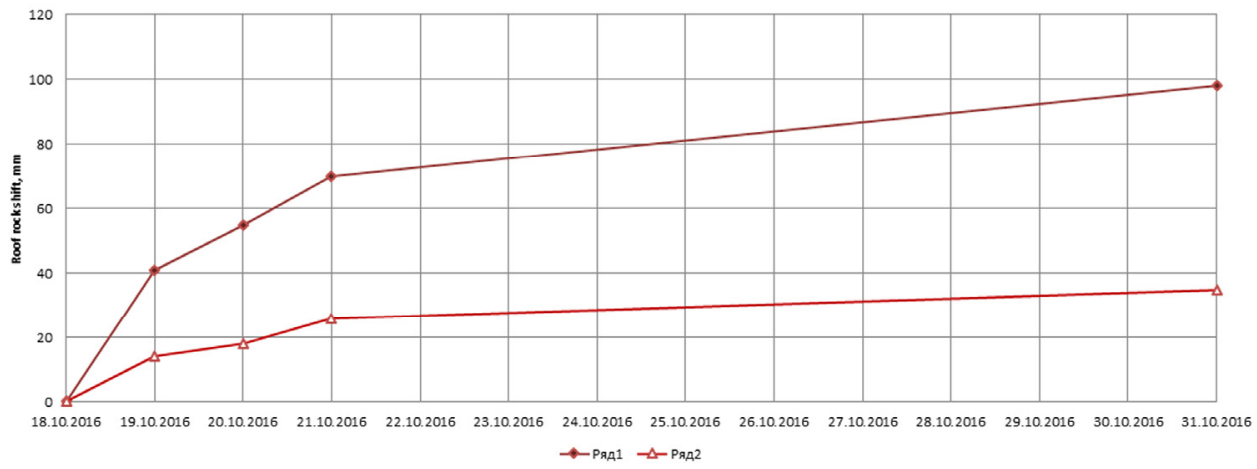

Fig. 3. General roof rock shift during observation (stations RG3-1 and RG3-2).

According to the results of borehole VEK 1 study using borehole endoscope in the roof of the drift when the distance between the borehole and face was $1 \mathrm{~m}$ the authors obtained the data characterizing rock discontinuity. The data fully comply with the readings of the three-wire extensometer when borehole depth was equal to $0-0,11 \mathrm{~m}$ (vertical fracture); 0,11 $0,20 \mathrm{~m}$ (stratification, fractured rock); 0,32-0,41 m (vertical fracture); 2,05-2,11 m (slant fracture); 2,35-2,36 m (slant fracture); 3,95 m (slant fracture); 5,48-5,67 m (fractured rock). This confirmed high forecast accuracy of the developed numerical models (up to 95\%).

\section{Conclusions}


Driving procedures and technology of using supports in development excavations imply coal mining by means of road header. The authors recommend to make excavations using road header with cutting boom and installation of roof bolts not closer than $0,8 \mathrm{~m}$ from the face line to avoid considerable roof rock stratification and rock falls.

It is possible to enhance the efficiency of supports in the excavations using arched or trapezium-shaped cross-cut when roof coincides with rock bolts and cable bolts in conjunction with channels and beams.

Enclosing rock intense relaxation zone is $20-30 \mathrm{~m}$ from face line. At the same time roof rock shifts can reach $100 \mathrm{~mm}$.

To avoid overloading and rupturing of the rock bolts during roof rock relaxation it is necessary to use primary and secondary support with yielding not less than $100 \mathrm{~mm}$.

Installation of secondary support should be made 15-20 m away from the face. It is necessary to take roof rock bolts with yielding which corresponds to relaxation of roof rock.

The developed numerical models let make an accurate forecast of roof rock deformation parameters in mine excavations located under conditions of V-12 (JSC "Urgalugol") when there is high tectonic stress.

\section{References}

1. I. G. Tarazanov, Ugol', 3, 36 (2017)

2. Z.T. Bieniawski, Bieniawski strata control in mineral engineering, 212 (NewYork: Wiley, 1987)

3. D.H. Loubscher, Trans. Instn Min. Metall., 93 (1984)

4. D. H. Laubscher, Trans. S. Afr. Inst. Min. Metal., 9:10 (1990)

5. A. D. Sashurin, N. P. Vlokh, A. V. Zubkov, V. M. Tsaregorodtsev, Soviet Mining Science, 1:42 (1968)

6. G.M. Molinda, K.A. Heasley, D.C. Oyler, J.R. Jones, Effects of horizontal stress related to stream valleys on the stability of coal mine openings: U.S. Bureau of Mines Report of Investigations, 26 (1992)

7. C. Mark, T.P. Mucho, U.S. Bureau of Mines Technology Transfer Seminar, 94:01, 53. (1994)

8. T.P. Mucho, C. Mark, Proceedings of 13th International Conference on Ground Control in Mines, Morgantown, 2:4, 277 (1994)

9. J.F.T. Agapito, L. Gilbride, W. Koontz, Proceedings of the 24th International Conference on Ground Control in Mining. Morgantown, 196 (2005)

10. J. A. Hudson, J. P. Harrison, Engineering Rock Mechanics: An Introduction to the Principles, (Elsevier Ltd. 1997)

11. T.G. Sitharam, V. Vijay Kumar Geotechnical \& Geological Engineering, 16:2, 129 (1998)

12. S.S. Peng, Longwall Mining. 2nd ed. Morgantown, (WV: West Virginia University, 2006)

13. G. G.Shtumpf Russian Journal of Mining Sciences, 4:30, 43 (1994)

14. R.O. Davis, A.P.S. Selvadurai, Plasticity and Geomehanics, (Cambridge: Cambridge University Press, 2002)

15. H. Kose, C.O. Aksoy, Numerical Modelling for the Recovery of Safety Pillars, (Lambert Academic Publishing, 2010) 